\title{
HUSSERL'S EPOCHE AS METHOD AND TRUTH
}

\author{
ROBERT D. WALSH
}

Marquette University

"We wish to proceed here by beginning anew...."

\section{The Practice of Transcendental Phenomenology}

The purpose of this paper is to show how, contrary to some commentators, Edmund Husserl's notion of the epoche, the bracketing or suspension of "naive" consciousness in favor of the phenomenologically "reduced" point of view, is an indispensable aspect of the practice of the phenomenological method. ${ }^{2}$ But the epoche is not merely an instrumental means. While it does function as a means, it is not merely an instrumental means because the epoche is simultaneously itself the end toward which it is a means, viz, the realization of apodictic knowledge as a lived process rather than a final solution. To treat Husserl's phenomenological reduction as merely an instrumental method for grasping and presenting the absolute essence of this or that truth would be already to have missed the subtler dimensions of both method and truth in Husserl's transcendental phenomenology.

In order to adequately describe what the epoche "is," in accordance with the principle of presuppositionlessness established by the epoche, it would be necessary already to have achieved the phenomenological perspective to which the epoche leads. The epoche cannot properly be grasped from the perspective of what Husserl calls the "naive" or "natural attitude" because it is precisely this kind of common-sense positivism that the epoche was designed to overcome. This "overcoming" is not merely an epistemological problem of "perspective," of getting the "right" interpretative slant on the epoche, but a problem of the fundamental difference between the unreflective, objectivistic orientation of the natural attitude, and the absolute freedom from bias that is to be achieved by virtue of the transcendental reduction. Therefore, to make the epoche itself an "object" of investigation placed "over and against" the investigating consciousness, as a possibility of being grasped and

${ }^{1}$ Edmund Husserl, The Crisis of European Sciences and Transcendental Phenomenology, trans. David Carr (Evanston: Northwestern University Press, 1970), III A, Sect. 43, p. 154; hereafter 'C'.

${ }^{2} \mathrm{H}$. Spiegelberg, e.g., claims that the epoche is "not indispensable" and can even become "hazardous and...falsify the approach to the phenomena...." The Phenomenological Movement (The Hague: Martinus Nijhoff, 1984; 3rd cd.), pp. 710-11. 
described as it really is, is to remain ensnared in exactly those sedimentary presuppositions which, according to Husserl, render philosophical apodicticity impossible.

There is precedent for our disclaimer here. From Ideas I on, Husserl himself relentlessly confronts his own slipping back into the natural attitude after the epoche has been performed, criticizing, for instance, his use of spatial metaphors to describe various aspects of the transcendental sphere, terms such as "above," "stratum," and "component." These metaphors, Husserl says, "taken from the sphere of the natural world . . . are dangerous" and, if they are to be used, a "necessary transformation of their sense must be noticed" (C, III A, 51, p. 174). This transformation of sense is the linguistic equivalent of the transformation of consciousness brought about by the epoche itself. Language thus becomes a "transcendental problem" or "region" whose true nature will only be uncovered through further transcendental analyses (C, III A, 55, p. 188). We will return to this important question of language in Section 4 below, in the context of Husserl's essay "The Origin of Geometry" and The Crisis.

The epoche is not merely a device or technique that can be used to "adequately" excavate self-evident truth. The epoche is not a tool. The only "tool" of transcendental phenomenology is the experience of the phenomenological investigator himself or herself. The only "technique" employed is an actual self -transformation, the achievement of a new, reflective "naivete," a fundamental change-of-attitude that is a lived posture of the investigating consciousness (C, III A, 40, p. 150). In short, one cannot fully understand the epoche without first undertaking it.

\section{Incipient Forms of the Epoche in Husserl's Early Work}

It is possible to trace the history of Husserl's development of the epoche from its emergence in his early works where it first appears, according to our argument, in seminal form, to its maturity in The Crisis. In his Logical Investigations (1900), Husserl discusses the essential principle of his phenomenological investigation of the ground of universal knowledge as a certain "thinking over" which is a "freedom from presuppositions" (LI, II, 7, pp. 263-64). ${ }^{3}$ Husserl amplifies this principle of presuppositionlessness by saying that it is more of a "shedding of light" than factual explanation: "Its aim is not to explain knowledge in the psychological or psychophysical sense as a factual occurrence in objective nature, but to shed light on the ldea of knowledge in its constitutive elements and laws" (LI, II, 7, p. 265). Once the constitutive dimension of the "mind" is recognized, "adequate" or "fulfilled" knowledge can no longer be deduced from principles or objects which somehow exist "in-

${ }^{3}$ Edmund Husserl, Logical Investigations, 2 vols., trans. J.N. Findlay (Halle, 1900; New York: Humanities P'ress, 1970); hereafter 'LI'. 
themselves," independent of the mind in the Kantian sense. A new "freedom" is now required in order to detach the phenomenological consciousness from the "prejudice" of objectivity and the unquestioned bias of naive empiricism.

This theme is reiterated in "Philosophy as Rigorous Science" (1911) in terms of freedom from "historicism," the bias which assumes that history can be made into an "object" to be grasped independently of the historical subject who is always already involved in that process, always already immersed in the ongoingness of history. ${ }^{4}$ Insofar as the subjective selfconsciousness is itself historical ("historicity"), the objectification of the historical ("historicism") will always fail to arrive at the true, or fully "valid" essence of any historical "ob-ject." Rather, what is needed, Husserl asserts, is an "entering vitally into an historically reconstructed spiritual formation" through "philosophical intuition" and "the phenomenological grasp of essences" (PRS, p. 128, 147). But this is not merely a methodological or theoretical problem. It is rather a response to a "spiritual need" which "afficts us, a need that leaves no point of our lives untouched" (PRS p. 140). In order to overcome these difficulties which are virtually ignored by empiricism, naturalism, and historicism, a radically new "science" is needed. Far from avoiding the historical content of the philosophical tradition, this radically new procedure must "penetrate the soul" of the tradition's words and theories.

History, as with language, thus becomes a "region" of phenomenological analysis for Husserl. The meaning of history demands an intentional analysis itself, an analysis of the essence of history (its "fundamental structures") as the constituted correlate (what will become the 'noema') of historical self-consciousness. History is not simply "there" for us, like a rock is "there" for empirical science. Rather, we make history. Thus, no particular answers to historical problems, the positional truths of "Weltanschauugen," the "particular" sciences, can ever be final, apodictic answers. A universal, "scientific" philosophy is needed, Husserl argues, which "for the sake of time" does not "sacrifice eternity" (PRS, p. 141).

It is exactly through the epoche that, Husserl believes, this "scientific clarity" can be achieved. Like history itself, however, the epoche cannot be grasped as a scientific "object." It is a process of self-transformation, "rising from below" ([RRS, p. 147) Husserl says, a "living" methodology which is non-conceptualizable as such. One cannot merely think one's way through the "universal" epoche. The epoche, as a continual approach to the origin of its own being, is always a doing again, always a beginning anew. "Philosophy," Husserl says, "is essentially a science of true beginning" (PRS, p. 146). Perhaps that is why Husserl himself returned to

${ }^{4}$ Edmund Husserl, "Philosophy as Rigorous Science" in Phenomenology and the Crises of Philosophy, trans. Quentin Laure (New York: Harper and Row, 1965); hereafter , 'I'RS'. 
the epoche again and again; not because of any inherent defect or failure of earlier attempts to formulate it, or because he did not yet have the procedure worked out "right," but because this "beginning again," as Merleau-Ponty also realized, is itself the essence of philosophy. Perhaps, also, that is why Husserl's Ideas, Cartesian Meditations, and The Crisis are all subtitled "Introductions" to phenomenological philosophy. Had Husserl lived longer, one wonders how many more "Introductions" there might have been.

\section{The "Cartesian" Reduction}

Concerning the "Cartesian" reduction, it will be helpful to keep in mind from the outset Husserl's own later assessment of this earlier approach. In The Crisis, Husserl criticizes the "Cartesian" approach to the reduction as having "a great shortcoming" in that it prematurely achieves the transcendental "in one leap," and consequently finds itself involved with a transcendental "ego" that is "empty of content" -- merely the bare universal which has not yet been fully explicated (C, III A, 43, p. 155). This is the epoche we discover in Ideas $I^{5}$ What is helpful about it is that it brings to light for the first time in Husserl's' work, the fundamental technical problems of transcendental phenomenology, problems that will be carried over, re-thought, and expanded in The Crisis. The "Cartesian" reduction, however, lacks a resolution for the "how" of intersubjective world-constitution, as well as recognition of the essentially personal and communal dimensions of the later formulations of the transcendental which will be described below.

Husserl's groundwork for the phenomenological reduction in Ideas I, if not the actual undertaking of it, is laid out in a series of stages in the first four chapters of the text. This development has a rather sudden and unexpected culmination at the end of Section 46 where Husserl declares without reservation that his inquiry has already "reached its climax" insofar as he has now achieved that peculiar kind of knowledge which is the foundation of the reduction and which, consequently, will allow for "the detachability in principle of the whole natural world from the domain of consciousness...." This knowledge is the work of "the region of pure consciousness" in the ego's immanent reflection upon (intentional) experience (Erlebnis) (Ideas, 1, 46, pp. 131-32). (It should be noted that in The Crisis, 'experience' is referred to primarily and consistently as

${ }^{5}$ Edmund Husserl, Ideas: General Introduction to Pure Phenomenology, vol. I, trans. W. R. Boyce Gibson (1913; New York: Colier Books, 1962); hereafter, Ideas. 
"Erfahrung," whereas in Ideas $I$ both Erlebnis and Erfahrung are used, sometimes interchangeably.) ${ }^{6}$

Husserl is well aware of the fact that the establishment of this region of pure consciousness (and hence the very possibility of the reduction) is wholly dependent upon the fundamental distinction between the experience (Erfahrung) of things or objects that are "transcendent," and the essentially different type of reality which is experience (Erlebnis) given through immanent reflection. The former (Erfahrungen), although predelineated in a manner which is apparenlly complete, are necessarily perspectival, spatial, always inadequate to their objects and, at best, are only able to be adumbrated or sketched out in a partial and contingent way. The latter (Erlebnisse), however, are not spatial objects, not "presented" at all. They have no sides as such. They can be perceived "immanently" and only immanently and are "given," therefore, according to Husserl, indubitably and absolutely.

Now even though a mental process, that is, an inner experience, is given absolutely in its "presentation," nevertheless, "in respect to its essence" it is a part of the whole stream of mental life and consequently can never be grasped in "its full unity" or completeness. But this "incompleteness" of the essence of an experience in regard to the whole stream of experiences is essentially different, Husserl contends here, from the incompleteness of the experience of a physical thing, which is always transcendent and is restricted, therefore, not only in terms of possible future perceptions, but also in terms of the perspectival limitations of the sensual perception of the thing within any given perceptual "now." There is some similarity between these incompletenesses, Husserl allows, but a radical, essential difference in their transcendent and immanent potential to be grasped. In any "now" of any immediate, given experience, there is a full, adequate and absolute apprehension of the essence of that "now". Not so with transcendent, spatial objects.

It is not merely the immediate, marginal background, Husserl tells us, that is a part of the perceptual field of the thing, but beyond this (we learn from reflective consciousness), there are other fields in which other objects could also arise in connection with the present perceptual field, continuously and harmoniously, in terms of what is meaningfully possible; all joined together in "concatenations" to form my "noticeable ficld" which, in turn, gives rise to the particular object that is there at this moment "for me." In other words, the immediate background of the object does not constitute the whole field of the object perceived because this background or any part of it could, at any moment, become the object of another field, and so on, throughout the whole realm of possible universes.

${ }^{6}$ Erazim Kohak, Idea and Experience: Edmund Husserl's Project of Phenomenology in 'Ideas I', (Chicago: University of Chicago Press, 1978), pp. 156-58. 
The existence of other perceiving subjects does not alter this situation for Husserl, since, as transcendent objects themselves (for me), other perceiving subjects would merely be included in my perceptual world and $I$ in theirs by virtue of being connected through the harmonious motivational concatenations which give rise to my current sphere of perception in the first place. Just as all possible "worlds" would be included in any given perceptual sketch -- grounded in harmony with my present sphere -- so too all possible perceiving subjects. This initial handling of intersubjectivity, subject to the charge of idealistic solipsism, will be developed by Husserl into an understanding of the transcendental ego as a "community of monads" in Cartesian Meditations, and, furthermore, as will be shown below, will be brought to an even more passionate, personal, and far-reaching realization in The Crises. Here, as we will see below, the philosopher will be called upon to be the selfreflection of mankind.

In the final analysis, the Cartesian epoche, along with the "constitutive" dimension of consciousness (the noesis/noema structure) which would require a separate discussion itself, establishes for Husserl "an absolute sphere of materials and noetic forms" which can be grasped and described in their purity by the phenomenologist as the real truth of the perceptual process, an "ultimate source" that Husserl believes offers "the only conceivable solution of the deepest problems of knowledge." The intentional analysis of the real components of perception would provide, if Husserl is correct, "objectively valid knowledge" (Ideas, I, 97, p. 263). In other words, given the claim of the phenomenological reduction to secure an absolute vantage point, together with the claim of the constitutive nature of intentionality, the world of transcendent objects "out there" is now understood to be wholly phenomenal or "irreal," and the underlying truth or real (reelle) process of perception can now be grasped through intentional analysis and 'pure' phenomenological description.

\section{The Reduction from the Lived World}

In contrast with the Cartesian variation of the epoche, the phenomenological reduction as Husserl works it out in The Crisis has more of a practical (ethical) and "spiritual" orientation than the more "scientifically rigorous" renderings of Ideas $I$ and Cartesian Meditations. Those early probings into the "new region" achieved through the reduction, in our view, are propaedeutic to what appears in its maturity in The Crisis. It is true, to a certain extent, that the reduction is one and the same throughout. But this "sameness" does not diminish the important differences that separate the "earlier" from the "later" Husserl. Husserl's thinking itself must be understood as "a constant becoming through a constant intentionality of development" (C, Appdx IV, p. 338). 
Husserl reveals this shift of attitude regarding the epoche in the connection between language and thought as this is expressed in "The Origin of Geometry," an essay from about the same period as The Crisis.? Husserl's theory of linguistic signification put forward in this late text views language as a "linguistic living body [Sprachleib]," a "linguistic embodiment" (OG, p. 161) of originative meaning which can be repeatedly re-lived and thus continued by others (OG, p. 164). A similar appreciation of language can be found in Merleau-Ponty's Phenomenology of Perception, especially the chapter entitled "The Body as Expression, and Speech." 8 The problem here is that there is a "seduction of language," a tendency of words and concepts to become sedimented "in the form of persisting linguistic acquisitions," so that the "self-evident structures" of "originally intuited life" must be repeatedly taken up and given new life (OG, p. 165). This is the task of the phenomenological philosopher working within the context of the epoche. Language is being pushed here "beyond" the limiting horizon of the world, beyond second-order, sedimented, purely "functional" language into the "life-world," the lived-world, the prereflective world of inter-subjective self-consciousness.

In The Crisis Husserl does not call the reader to the stark methodological manipulation of the "object" that is found in the ruminations of ldeas $l$, but to a radically personal "self-transformation." We are not merely "called" to a new way of seeing, to a certain "perception" of a new region of "being," but to a new "way of being." This ethical demand emerges from Husserl's new pluralistic understanding of the transcendental ego. The term "ego" is really a misnomer here. This "ego", this individual "l," is already a plurality, already a "we", a community involved in a pre-given "life-world."

In The Crisis we are called to a new way of life. For philosophers, this way of life is understood in terms of the whole of mankind. Philosophers are called to be mankind's most essential self-reflection (C, Appdx IV, PP. 335-41). The primary philosophical concern will no longer be the "what" of the metaphysical question, but the "how" of it. The humanistic motivation of the epoche takes precedence here over the already resolved technical problems. What is essential is that we practice the epoche and live it "as a habitual attitude which we resolve to take up once and for all" (C, III A, 40, p. 150) over and over again. At one point in The Crisis, Husserl goes so far as to describe the initial recognition and acceptance of this "call" to take up the epoche as comparable to a religious experience! "Perhaps it will become manifest," Husserl says,

${ }^{7}$ Edmund Husserl, "The Origin of Ceometry," in Jacques Derrida, Edmund llusserl's Origin of Geometry: An Introduction, trans. John P. Leavey, Jr. (1939; New York: Nicholas Hyas, Lid., 1978), pp. 157-180; hereafter 'OC'.

${ }^{8} \mathrm{Cf}$. my paper, "An Organism of Words: Ruminations on the Philosophical-I'octics of Merleau-P'onty," Kinesis, 14, no. 1(1984): 13-33. 
that the total phenomenological attitude and the epoche belonging to it are destined in essence to effect, at first, a complete personal transformation, comparable in the beginning to a religious conversion, which then, however, over and above this, bears within itself the significance of the greatest existential transformation which is engaged as a task to mankind as such (C, III A, 35, p. 137).

What does it really mean that the full, "universal" epoche is "comparable" in the beginning to a "religious conversion?" We must read this keeping in mind that Husserl has explicitly warned against misinterpreting transcendental phenomenology as any kind of mystical or supermundane "transcendentalism," while at the same time recalling that he does not for a moment deny that phenomenology, as a philosophical way of life, is a thoroughly spiritual process with a "spiritual heritage" and a "spiritual unity" in which it is the task of the individual philosopher "to carry forward...the self-reflection of his forebears...the chain of thinkers, the social interrelation of their thinking, the community of their thought, and transform it into a living present for us..." (C, 1I, 15, p. 47). The epoche has now taken on the monumental proportions of world-transformation.

By the time of The Crisis, the concept of the transcendental has come to include all self-conscious beings, even, Husserl suggests, animals, plants, and "all living beings insofar as they have, even indirectly but still verifiably, something like 'life,' and even communal life in the spiritual (geistige) sense" (C, III A, 55, p. 188). This primordial communion has a collectively pre-given world-horizon within which "objects" are experienced in their immanent, intentional givenness, i.e., intuitively, as "objects." Husserl is clearly less interested here in the ontological status of these "objects," whether or to what extent they are "real" -- the "scientific" point of departure of the "Cartesian" reduction - and more interested in the lived experience of the existential subject, the experience that is more primary than the superficial activity of consciousness in the natural attitude. Here, "through the epoche a new way of experiencing, of thinking, of theorizing, is opened up" in which the philosopher "forbids himself to ask questions which rest upon the ground of the world at hand, questions of being, questions of value, practical questions, questions about being or not-being, about being valuable, being useful, being beautiful, being good, etc." (C, III A, 41, p. 152). Asking "about" is always an asking from within the horizon of the world. But what Husserl is interested in here is the "pure" subject as constituting, transcendental intentionality which, through the epoche, has achieved the "perspective" of a groundless "above" and "beyond" the world where "all natural interests are put out of play" (C, III A, 41, p. 152).

In Section 47 of The Crisis Husserl describes how the attitude achieved by the reduction is not an isolated one, and hence is defensible 
against the charge of solipsism (initially worked out in Cartesian Meditations). Husserl argues that "in our continuously flowing worldperceiving we are not isolated but rather have within it, contact with other human beings landl in living with one another each one can take part in the life of the others" (C, III A, 47, p. 163). This fundamentally communal nature of the transcendental "ego" is, if not a "new" development, certainly an advancement over the earlier formulation found in the fifth of the Cartesian Meditations. Where the horizontal/vertical approach to the transcendental in The Crisis is preeminently personal, intersubjective, world-oriented and historical, the earlier Cartesian approach is skewed toward the positivistically analytic and the "scientific" and thus results in an isolated, "empty" transcendental ego that is purely vertical, and thus lacks the horizontal transcendence toward the "other" which emerges in the epoche of The Crisis. The Cartesian epoche is, according to Husserl's own assessment, phenomenologically inadequate (C, III A, 43, p. 155).

In The Crisis the transformation of the whole person through practicing the epoche becomes a "vocation," a "habit," a way of life, something which must be lived every day as an ongoing, intersubjective self-transformation. If Ideas I laid out the bare possibility (theoria) of the epoche as method and goal, The Crisis depicts the reality of this earlier, more abstract epoche as actually being accomplished in terms of lived and living praxis. This is "the quite personal responsibility of our own true being as philosophers," Husserl says, "our inner personal vocation (which) bears within itself at the same time the responsibility for the true being of mankind." Philosophers are thus "functionaries of mankind." There is an inherently practical orientation to phenomenology, an ethical dimension. This involves, not the mere reflection upon, but the practice of the epoche. Husserl claims that "together with the new task (of phenomenology) and its universal apodictic ground, the practical possibility of a new philosophy will prove itself: through its execution" (C, I, 7, pp. 17-18). The radicality of this dimension of praxis is that it is a process whose uniqueness rests in its being the ground of its own being:

In the epoche neither logic nor any a priori nor any philosophical demonstration in the venerable old style can provide us with artillery. Rather, like all objective-scientific disciplines, they are naive and are themselves to be subjected to the epoche. On the other hand, what is peculiarly proper to the essence of the incipient philosophy of this phenomenological-transcendental radicalism is that, as we have said before, rather than having a ground of things taken for granted and ready in advance, as does objective philosophy, it excludes in principle a ground of this or any other sort. Thus it must begin without any underlying ground. But immediately it achieves the possibility of creating a ground for itself through its own powers, namely, in mastering, through original self-reflection, the naive world as 
transformed into a phenomenon or rather a universe of phenomena. (C, III A, 53, p. 181)

This is why, as Richard Cobb-Stevens points out, "the auto-constitution of the ego cannot be thematically displayed but only obliquely disclosed." 9 Thus in his new version of the epoche Husserl says that he will "lead" but not "instruct" us (C, $I, 7,18)$. In response to our personal/transcendental "call," we must take up and practice the epoche.

The core responsibility of this "vocation" is found in the directive to abstain from the thesis of the common world. We must withdraw from all worldly interests and influences and become "disinterested spectators," participant-observers looking on at our own looking-on (C, III A, 41, p. 151). But at the same time we must not forget that we are also immersed in a pre-given life-world. "Thus in a certain sense the philosopher within the epoche must also 'naturally live through' the natural life; yet the epoche effects an immense difference in that it changes the entire manner of investigation and, furthermore, reshapes the goal of knowledge in the whole of its ontic meaning" (C, III A, 52, p. 176).

Although he characterizes the achievement of the full reduction as a "position above" the finite manifestations of the transcendental, Husserl nevertheless admits that there are problems of language here which may result in one's being misled: "to be sure, words taken from the sphere of the natural world .... are dangerous, and the necessary transformation of their sense must therefore be noticed" (C, III A, 51, p. 174). This necessary transformation of sense "elevates" these spatio/temporal "signs" to the transcendental sphere where there is no space and a radically different notion of time.

The epoche as it is re-formulated in The Crisis contains Husserl's answer to the problem, not only between philosophy and science, but to the larger "spiritual" crisis of the Western world as a collectively constituted phenomenon. World transformation is called for here through individual self-transformation, accomplished through the practice of the epoche. The constitutive operation of the transcendental "ego" in The Crisis involves the orchestration of a spiritual community which, through the practice of the epoche, achieves the mature development of ontic validity in self-evident experience and now begins taking "responsibility" for itself and all others in the world.

${ }^{9}$ Richard Cobb-Stevens, "Transcendental and Empirical Dimensions in Husserl's Phenomenology," in Continental Philosophy in America, ed. Hugh J. Silverman, et al. (Pittsburgh: Duquesne Univ. Press, 1983), p. 31. 


\section{The 'Reduction from I'sychology'}

The themes of the reduction from the "Lebenswelt" are continued in Husserl's inductive consideration of the possibility of establishing the principles of transcendental phenomenology from the work proper to psychology, the work that deals with the possibilities of soul. Husserl asserts that "what is essentially proper to the soul includes all intentionalities, the experiences of the type called 'perception,' for example, considered precisely as those performed by the person serving as an example and exactly in the way he accomplishes them; and always lone must take carel that nothing is brought in which goes beyond the person's or the 'soul's' own essence" (C, III B, 69, p. 236). It is the "soul" itself that is the "object" of correlation here and the manner in which experience is given to this soul. Epistemological concern for the ontological status of the "objective" world has been superceded by a concern for the manner in which the individual experiences that world. Thus, for Husserl, "whether the perceived lobjectl exists or not, whether the perceiving person is mistaken about this or not, and also whether $I$, the psychologist, who in my empathetic understanding of the person unhesitatingly concur in the belicf in the perceived [object], am mistaken about it or not - this must remain irrelevant for me as a psychologist" (C, III B. 69, p. 236). These things must not interfere with the pure psychological description of the perception. What is of central importance here is the existing individual. "For psychology is, after all, supposed to be the universal science of souls, the parallel to the universal science of bodies; and just as the latter is from the start a science through a universal 'epoche through a habitual, vocational attitude established in advance in order to investigate abstractively only the corporeal in its own essential interrelations, so also for psychology" (C, III B, 69, p. 239).

Husserl's formulation of the reduction from psychology in The Crisis offers a specific picture of the kind of radical self-transformation required by the "full" epoche. First of all, Husserl says, "the epoche must be actually universally carried out." It must not be merely a shallow, critical epoche, or "a universal critique of experience" offering the possibility of knowing "truths-in-themselves," or a "skeptical, agnostic epoche. The full epoche will be none of these. These false epoches all succumb to the omnipresent temptation of the natural attitude; they are "positional" assertions, Husserl argues. "But the psychologist as such in his inquiry must, we repeat, take and have no position." And, we might add, the same is true for the phenomenological philosopher. It is only through this prejudice-free, transcendental "posture" that the psychologist will achieve full intentional unity, full realization of the "absolutely self-enclosed 'internal' world of .... conscious| subjects," that is, for the phenomenological psychologist, the "total unity of the intentional life as his horizon of work" 
(C, III B, 69, p. 240). A "therapeutic" dimension of the epoche is revealed here. The achievement of the attitude of the 'disinterested spectator' ("disinterest" as a non-positional "position" requires further analysis) is both the prerequisite and the goal of the process. Both the psychologist and the subject, as co-habitants of a single, created world, already copenetrate the transcendental realm, in a manner that reflects the relation between the "sub-community" of philosophers in its relationship to "mankind" as mankind's self-reflection.

\section{Conclusion}

A key difference between the "earlier" and "later" reductions is that the later formulation of the epoche is established out of the context of a pre-given world-horizon, a horizon within which particular experiences arise and to which they are inextricably bound in terms of the logic of possibility of the object and the unity of the "inner" and "outer" horizon of the thing. This is "the lived world" in which we are always already immersed and which always exceeds our ability to comprehend or fully express it, as in Gestalt psychology where the whole exceeds the sum of its parts. Here the transcendental is revealed primarily as "lived" experience. The "Cartesian" reduction, on the contrary, attends to the object in terms of the continuous and harmonious correlation of a possible world of objects; but this world is generated from the structure of the object rather than from the pre-thematic "being there" in the world of the subject.

This confirms the general difference in tone between these two approaches to the reduction: where the "Cartesian" reduction is abstract and technical, the reduction from the lebenswelt is personal, communal, and bound to the spiritual, ethical, social, political, and psychological dimensions of life. It is because the "Cartesian" reduction lacks an experiential ground in the lived-world that Husserl came to see it as "empty" and as thus contributing to the slippage of the investigating, phenomenological consciousness back into the worldly mire of the natural attitude, a slippage or derailment which requires that the phenonenologist consciously work to get back on the track of the epoche, to begin anew, to initiate a fresh introduction to that process of phenomenological philosophy which is itself, in the beginning and the end, always a "science" of introductions. As Merleau-Ponty realized, the final lesson of the epoche is that no final lesson is possible. Despite the differences between earlier and later forms of the reduction in Husserl's philosophy, despite the fact that the epoche is inconceivable as such, that it presents a perpetual challenge to the claim to supremacy of representational thinking...despite this it should be clear that the epoche is, and always was, for Husserl, an indispensable aspect of the practice of the phenomenological method 
and, in its fulness, the guarantor of this method's end: apodicticity as an ethical way of life. 